\title{
OPEN Enhancement of phenolics content and biological activities of longan (Dimocarpus longan Lour.) treated with thermal and ageing process
}

\author{
Preaploy Hong-in ${ }^{1,2}$, Waranya Neimkhum ${ }^{3}$, Chanun Punyoyai ${ }^{2}$, Suwannee Sriyab ${ }^{2} \&$ \\ Wantida Chaiyana ${ }^{2,4,5}$
}

This study is the first to compare the chemical compositions and biological activities of a conventional dried Dimocarpus longan with a novel black $D$. longan that underwent a thermal ageing process. Pericarp, aril, and seed of both $D$. longan were macerated in $95 \% \mathrm{v} / \mathrm{v}$ ethanol. Their chemical compositions were investigated using a Folin-Ciocalteu assay, aluminum chloride assay, and highperformance liquid chromatography. Antioxidant activities were evaluated in terms of radical scavenging and iron (III) reduction capacity. An enzyme inhibition assay was used to evaluate the hyaluronidase inhibition. Inflammatory cytokine secretion was evaluated with an enzyme-linked immunosorbent assay. After being exposed to a heating and ageing procedure, gallic acid and ellagic acid content were increased tenfold, while the corilagin content was doubled. Black $D$. longan seed extract was the most potent anti-hyaluronidase and antioxidant with the strongest free radical scavenging and reduction power, while black $D$. longan aril extract resulted in the highest inhibition of inflammatory cytokine secretion. Black $D$. longan contained more biologically active compounds and possessed more potent biological activities than conventional dried $D$. longan. Therefore, thermal ageing treatment is suggested for producing black $D$. longan, for which seed extract is suggested as a cosmeceutical active ingredient and aril extract for anti-inflammation.

Dimocarpus longan Lour., a subtropical evergreen plant in the family of Sapindaceae, is widely known as longan. D. longan is cultivated in several countries in East Asia and South-East Asia as well as Australia and some subtropical regions in the US ${ }^{1}$. China and Thailand are the largest areas of commercial D. longan cultivation ${ }^{2}$. The succulent and edible aril with delicious flavor and health benefits has led to the increased popularity of $D$. longan ${ }^{1}$. Since the aril of $D$. longan contains several polyphenols, flavonoids, organic acids, and polysaccharides, it possesses various beneficial biological activities, including antioxidant, antiglycation, anticancer, immunomodulatory, prebiotic, anti-osteoporotic, anxiolytic, and memory-enhancing effects ${ }^{3}$. A decoction of dried aril has been taken as a tonic for insomnia and neurasthenic neurosis treatment since ancient times ${ }^{4}$. Not only does the aril of D. longan, which is the only edible portion, have reported beneficial effects on health, but the pericarp has also been reported to contain abundant polyphenols, flavonoids, and polysaccharides, which possess antioxidant, anti-tyrosinase, and anti-hyperglycemic activities ${ }^{1}$. Furthermore, $D$. longan seed, which is a waste from the food and canning industry, contains antioxidative polyphenols and possesses anti-tyrosinase, antibacterial, and antifungal activity ${ }^{1,5-7}$. D. longan seed has also been administered to counteract heavy sweating, whereas the ground kernel has been used for the treatment of various conditions according to their chemical components such as saponin, tannin, and fat ${ }^{8}$. Although $D$. longan has been reported to contain a variety of biologically active components and have the potential to be used for the treatment of various conditions, the fruit of $D$. longan has a short storage life since its pericarp rapidly turns brown and hardens at ambient temperature ${ }^{1,9}$. The highly perishable nature and limited shelf life of $D$. longan fruit not only decreases its marketing value after deterioration but also

\footnotetext{
${ }^{1}$ Master's Degree Program in Cosmetic Science, Faculty of Pharmacy, Chiang Mai University, Chiang Mai 50200, Thailand. ${ }^{2}$ Department of Pharmaceutical Sciences, Faculty of Pharmacy, Chiang Mai University, Chiang Mai 50200, Thailand. ${ }^{3}$ Department of Pharmaceutical Technology, Faculty of Pharmaceutical Sciences, Huachiew Chalermprakiet University, Samutprakarn 10250, Thailand. ${ }^{4}$ Research Center of Pharmaceutical Nanotechnology, Chiang Mai University, Chiang Mai 50200, Thailand. ${ }^{5}$ Innovation Center for Holistic Health, Nutraceuticals, and Cosmeceuticals, Faculty of Pharmacy, Chiang Mai University, Chiang Mai 50200, Thailand. ${ }^{\boxplus}$ email: wantida.chaiyana@gmail.com
} 


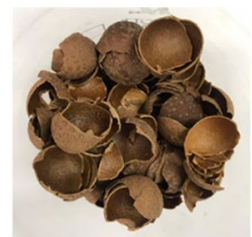

(a)

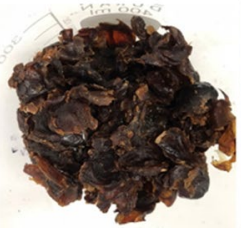

(e)

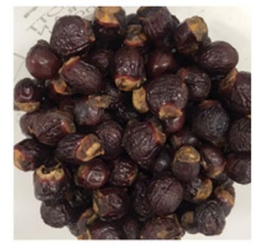

(i)

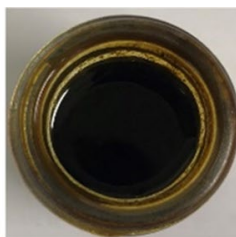

(b)

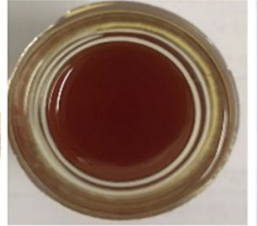

(f)

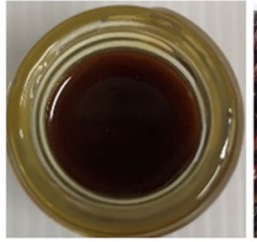

(j)

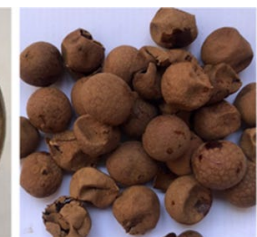

(c)

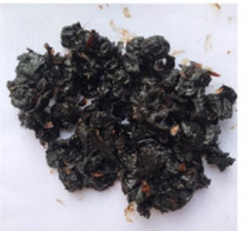

(g)

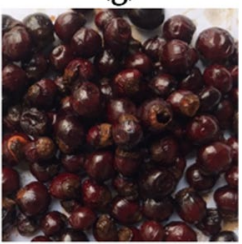

(k)

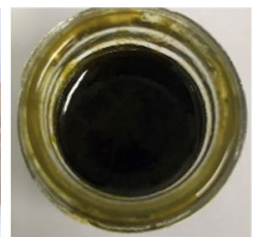

(d)

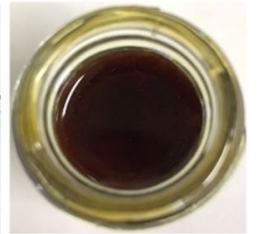

(h)

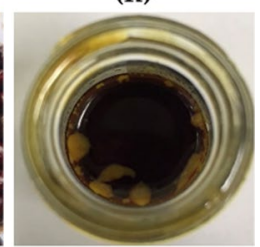

(1)

Figure 1. External appearance of dried D. longan pericarp (a), dried D. longan pericarp extract (b), black $D$. longan pericarp (c), black D. longan pericarp extract (d), dried D. longan aril (e), dried D. longan aril extract (f), black D. longan aril (g), black D. longan aril extract (h), dried D. longan seed (i), dried D. longan seed extract (j), black D. longan seed (k), and black D. longan seed extract (1).

burdens both domestic distribution and export to foreign countries ${ }^{10}$. Although a low temperature $\left(1-5^{\circ} \mathrm{C}\right) \mathrm{can}$ protect $D$. longan from pathological degradation, the fruit deteriorates quickly after being removed from cold storage $^{3}$. Moreover, the over-supply of off-seasonal $D$. longan production recently led to increasing production costs and a decrease in selling prices ${ }^{10}$. Sopadang et al. highlighted the issues in the D. longan supply chain and recommended adding value to $D$. longan and creating a range of $D$. longan products as improvement alternatives to enhance $D$. longan supply chain management efficiency ${ }^{10}$.

Dried flesh and the canned product of $D$. longan are widely consumed and can be distributed worldwide. Generally, dried foods can be kept for a long period, but their sensory and nutritional characteristics are often lost along with the water removal during the drying processes ${ }^{11}$. Production of intermediate moisture food (IMF) is another technique to overcome this problem since the properties of IMF are close to fresh foods while extending shelf life ${ }^{11,12}$. A reduction of the moisture content and a water activity below 0.6 do not support microbial growth and lead to shelf-stable products ${ }^{12,13}$. Various types of food have been preserved as IMF, such as meat and several fruits, e.g., grapes, tomatoes, peaches, prunes, apricots, and strawberries ${ }^{11,14}$. However, some antimicrobial compounds and additives are required in the production of IMF for antimicrobial properties (e.g., preservatives, sugar, and salt), along with the agents for water activity reduction and plasticizing, e.g., glycols and sorbitol ${ }^{12,13}$.

Besides IMF, the heating and ageing process can also prolong the shelf life without refrigeration. A well-known food that undergoes this process is black garlic (Allium sativum L.), a processed garlic produced by thermal treatment of raw garlic at high temperature and high relative humidity for 60-90 days without using additives ${ }^{15,16}$. During the production process, raw garlic also undergoes the Maillard reaction, which occurs between amine groups and carbonyl compounds, finally resulting in brownish melanoidin ${ }^{17}$. Melanoidin has been shown to have a number of biological actions, including antioxidant, antibacterial, anti-inflammatory, hypoglycemic, hypotensive, and antitumor effects; prevention of obesity; lowering of serum lipopolysaccharide levels; and modulation of the composition of the gut microbiota ${ }^{17,18}$. Additionally, inhibition of oxidation and angiotensin I converting enzyme were enhanced in black garlic comparing to raw garlic ${ }^{16}$.

Therefore, the heating and ageing process not only preserves the food but also enhances its biological activities. Since the production of black $D$. longan through a heating and ageing process has not previously been reported, this study is the first to produce a novel black $D$. longan and investigate its chemical composition, as well as its potential health benefits of antioxidant, anti-inflammatory, and anti-hyaluronidase activities.

\section{Results and discussion}

Dried $D$. longan and black $D$. longan extracts. The external appearance of dried $D$. longan is different from black $D$. longan as shown in Fig. 1 . The color of pericarp, aril, and seed of black D. longan was obviously darker than that from dried $D$. longan, especially the aril, which turned from dark brownish color to black. The pericarp and seed of black $D$. longan were substantially more moist than dried $D$. longan. The outer part of dried $D$. longan seed was shriveled, whereas the dried $D$. longan pericarp was dry and brittle. All D. longan extracts were of semisolid mass with different color as shown in Fig. 1. The color of black D. longan extracts was darker 


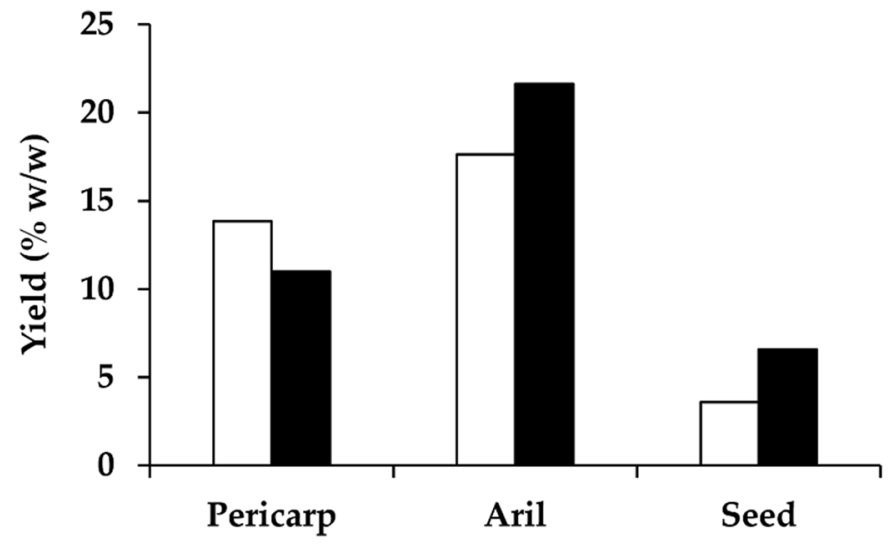

Figure 2. Yield of the ethanolic extracts from pericarp, aril, and seed of dried (unfilled squares) and black (filled squares) D. longan.

than the dried $D$. longan extracts. The color of pericarp extracts was the darkest, followed by the extract from seed and aril. Yields of each D. longan extract are shown in Fig. 2. The aril yielded the highest extract content, followed by pericarp and seed. The highest yield of the extract was obtained from black D. longan aril $(21.6 \% \mathrm{w} / \mathrm{w})$, followed by dried $D$. longan aril $(17.6 \% \mathrm{w} / \mathrm{w})$, dried $D$. longan pericarp $(13.8 \% \mathrm{w} / \mathrm{w})$, black $D$. longan aril $(11.0 \%$ $\mathrm{w} / \mathrm{w})$, black $D$. longan seed $(6.6 \% \mathrm{w} / \mathrm{w})$, and dried $D$. longan seed $(3.6 \% \mathrm{w} / \mathrm{w})$. It was highlighted that black $D$. longan yielded higher extract content compared to dried $D$. longan in aril and seed but not in pericarp. The explanation is that the pericarp of dried $D$. longan lost more water content than that of black D. longan, which underwent a heating and ageing process in conditions that kept the relative humidity constant at $75 \%$. Therefore, the mass of initial pericarp material of dried D. longan was lower and led to a higher extract yield since the yield was calculated from the initial pericarp material used in the extraction process.

Chemical compositions of dried D. longan and black D. longan extracts. Dimocarpus longan extracts were investigated for contents of total phenolic compounds, total flavonoid, gallic acid, corilagin, and ellagic acid. Gallic acid and corilagin are natural polyphenolic compounds which belong to hydrolysable tannin, whereas ellagic acid belongs to a flavonoid group ${ }^{19,20}$. Among different parts of dried D. longan, pericarp extracts contained the significantly highest total phenolic content $(\mathrm{p}<0.05)$ and the highest total flavonoids as shown in Fig. 3. The results agreed well with a previous study, which reported that polyphenolic compounds are abundant in pericarp and seed of $D$. longan compared to the D. longan aril ${ }^{1}$. The total phenolic content of pericarp, seed, and aril extracts from dried $D$. longan, which were $967.6 \pm 31.5,739.3 \pm 62.3$, and $229.5 \pm 2.6 \mu \mathrm{g}$ GAE per g extracts, were found to be in agreement with a previous study, which reported that the total phenolic content of D. longan was in the range of 22.09-132.47 mg gallic acid equivalent (GAE/100 g), which was equivalent to 220.9-1324.7 $\mu \mathrm{g}$ GAE per g extract ${ }^{1}$. Interestingly, the dramatic increase in total phenolic content was observed in black D. longan seed extract. The ethanolic extract from black D. longan seed contained as much as $1827.1 \pm 73.1 \mu \mathrm{g}$ GAE per g extracts, which was much higher than previously reported ${ }^{1}$. On the other hand, there was no significant difference between the total phenolic content of dried and black $D$. longan extract from pericarp and aril $(\mathrm{p}>0.05)$.

In addition to the total phenolic content, black D. longan seed extract also contained the significantly highest flavonoid contents $(\mathrm{p}<0.05)$. Among various dried $D$. longan extracts, the pericarp contained the significantly highest flavonoid content of $2.8 \pm 2.4 \mu \mathrm{g}$ QE per g extract as shown in Fig. 3 ( $\mathrm{p}<0.05)$. The results were in accordance with a previous study, which reported that the quercetin content of $D$. longan pericarp was $3.12 \pm 0.76 \mathrm{mg} /$ $\mathrm{kg}$, which was equivalent to $3.12 \pm 0.76 \mu \mathrm{g} / \mathrm{g} \operatorname{extract}^{21}$. D. longan pericarp has been reported to contain slightly higher content of flavonoids than $D$. longan seed and aril ${ }^{22}$. Obviously, the flavonoid content of black D. longan seed extract, which was as high as $13.6 \pm 2.5 \mu \mathrm{g}$ QE per g extract, was dramatically enhanced and was about four times higher than previously reported.

Although the thermal ageing process of $D$. longan did not affect the phenolic and flavonoid contents of $D$. longan pericarp and aril, the total phenolic and flavonoid contents of $D$. longan seed were obviously enhanced after the production process of black $D$. longan. The likely explanation might be the formation of biological compounds, which were not originally present in the D. longan seed, during the thermal ageing process such as resistant $\operatorname{starch}^{23,24}$. During the temperature/time-controlled incubation, the starch inclusion complexes were generated by interaction with other components in the seeds $s^{24}$.

As shown in Fig. 4, gallic acid (1), corilagin (2), and ellagic acid (3) were detected in D. longan extract. The peak of gallic acid, corilagin, and ellagic acid in the HPLC chromatograms were detected at around 3.7, 9.9, and $19.2 \mathrm{~min}$, respectively. The results agreed with the previous studies, which identified these compounds as major polyphenolic components of $D$. longan pericarp and seed ${ }^{25-27}$.

In the present study, the contents of these polyphenolic components were investigated in the context of a comparison between black D. longan extract and dried D. longan extracts. The amounts of each compound in $D$. longan extracts are shown in Fig. 5. The findings were in line with the total phenolic and total flavonoid contents 
(a)

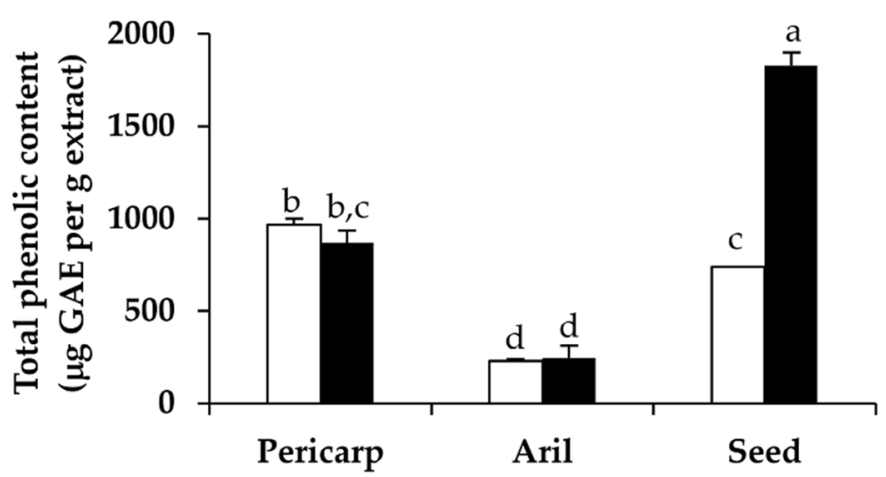

(b)

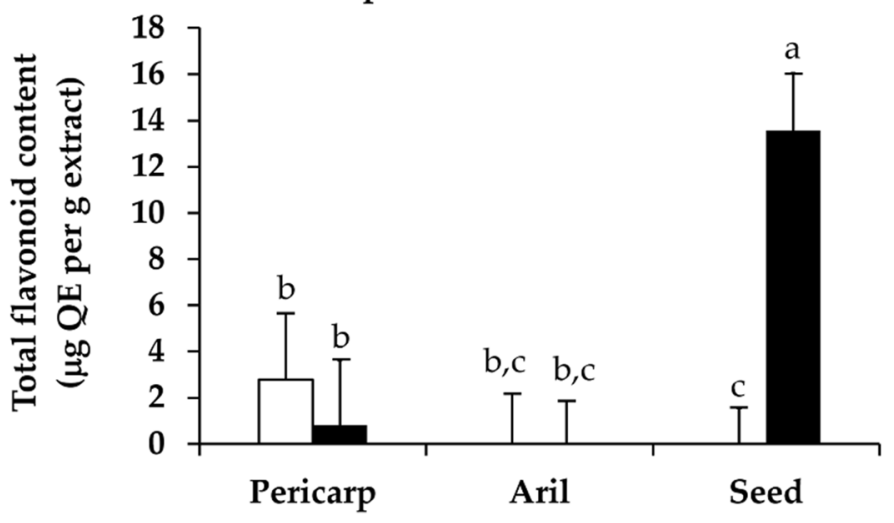

Figure 3. Total phenolic content (a) and total flavonoid content (b) of the ethanolic extracts from pericarp, aril, and seed of dried (unfilled squares) and black (filled squares) D. longan. The letters (a, b, c, and d) denote significant differences in total phenolic content or total flavonoid content among various $D$. longan extracts $(\mathrm{p}<0.05)$ when analyzed using one-way analysis of variance (ANOVA) followed by Tukey's post-hoc tests $(\mathrm{n}=3)$.

since black $D$. longan seed extract contained the significantly highest quantities of polyphenolic compounds and flavonoid contents $(\mathrm{p}<0.05)$.

Among various parts of dried $D$. longan fruit, seeds contained the significantly highest content of gallic acid, corilagin, and ellagic acid ( $\mathrm{p}<0.05)$ with $5.3 \pm 0.0,8.9 \pm 0.1$, and $1.9 \pm 0.2 \mathrm{mg} / \mathrm{g}$ extract, respectively. Interestingly, the these phenolic and flavonoid contents were significantly enhanced after the production process of black $D$. longan $(\mathrm{p}<0.05)$. The gallic acid, corilagin, and ellagic acid content of black $D$. longan seed extract were as high as $53.6 \pm 0.9,19.8 \pm 2.9$, and $24.5 \pm 0.7 \mathrm{mg} / \mathrm{g}$ extract, respectively. After being exposed to a heating and ageing procedure, the amount of gallic acid and ellagic acid of $D$. longan were increased by around 10-fold, while the quantity of corilagin was doubled. The reason might be the liberation of free polyphenolic compounds and flavonoids from the bound forms (i.e., esterified and glycosylate) or the decline in enzymatic oxidation involving in the antioxidant compounds in the raw fruit ${ }^{28}$. The results of black $D$. longan were in accordance with those of black garlic, as the total phenolic and total flavonoid contents of the garlic subjected to the thermal processing steps were significantly higher than those of fresh garlic ${ }^{23,28}$. The previous study reported that the phenolic content was increased by about 4-10-fold in the black garlic cloves compared with the fresh garlic ${ }^{23}$.

Apart from the findings showing differing content of the biologically active component in various parts of $D$. longan fruit, different methods used in the drying process also affected their bioactive compounds. The thermal ageing process was hence proposed for the enhancement of bioactive compounds in D. longan.

Antioxidant activities of dried $D$. longan and black $D$. longan extracts. The antioxidant activities of dried and black $D$. longan extracts were investigated by two assays with different mechanisms of action. The ABTS assays measure the electron transfer reaction and represent the radical scavenging activity of the tested samples, while the FRAP assay is concerned with the ion reduction process, which represents the ability of the tested compound to convert ferric ions $\left(\mathrm{Fe}^{3+}\right)$ to ferrous ions $\left(\mathrm{Fe}^{2+}\right)^{29}$. The ferric reducing antioxidant power $\left(\mathrm{EC}_{1}\right)$ and Trolox equivalent antioxidant capacity (TEAC) values of dried and black D. longan extracts are shown in Fig. 6.

The TEAC values of black $D$. longan extracts were not significantly different from those for the dried $D$. longan extracts, except in the aril. The dried $D$. longan aril extract had no antioxidant activity, whereas the black $D$. longan aril extract possessed some antioxidant activity with a TEAC value of $4.1 \pm 1.4 \mu \mathrm{g}$ Trolox/mg extract. A probable explanation lies in the greater Maillard reaction, which occurs in the aril as compared with the others. As D. longan aril is composed of glucose, fructose, and various types of amino acids, such as $\gamma$-aminobutyric acid, it tends to undergo Maillard reactions, which are the chemical reactions between an amino acid and a reducing 


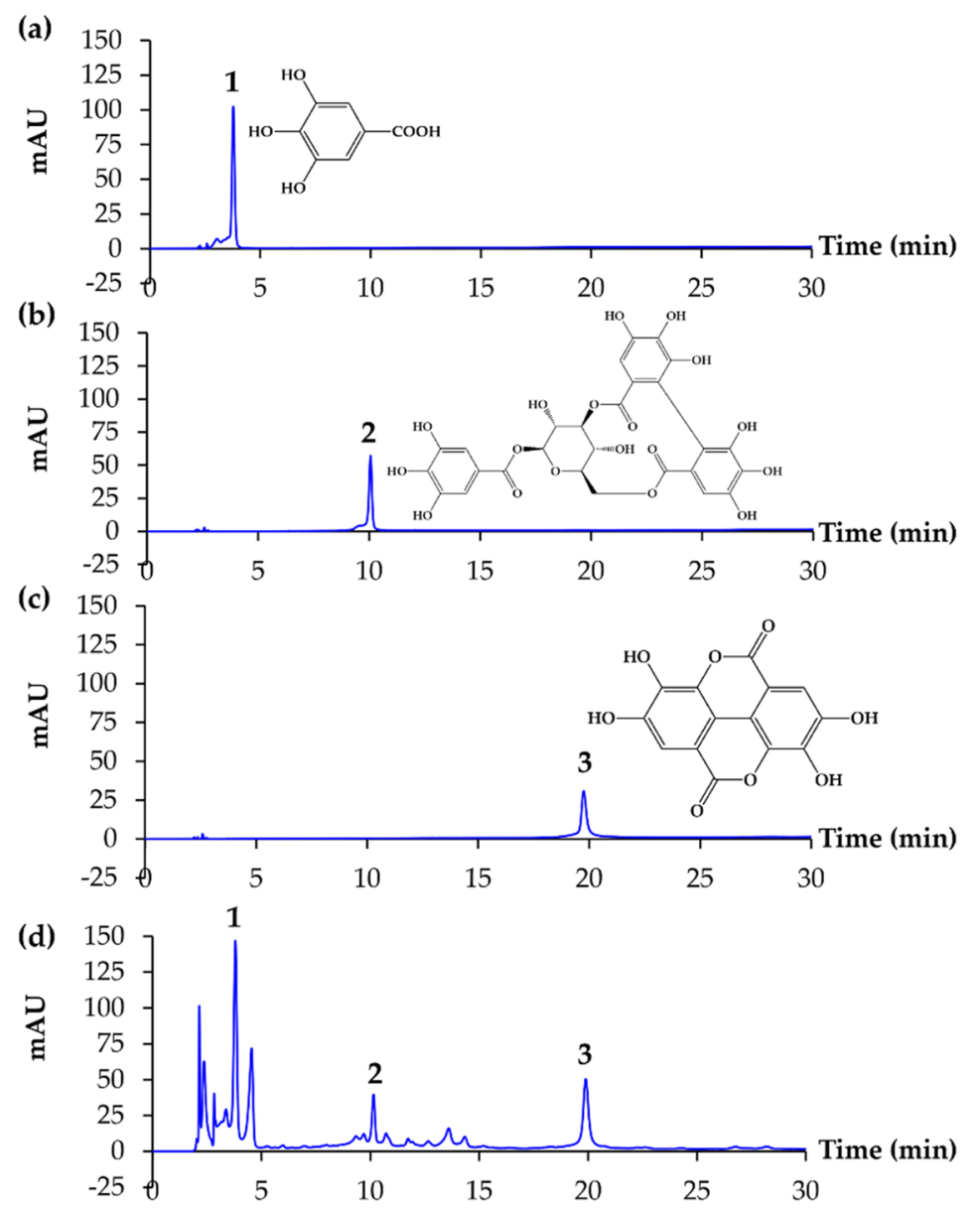

Figure 4. HPLC chromatograms of gallic acid (a), corilagin (b), ellagic acid (c), and black D. longan seed extract $(\mathbf{d})$.

sugar that occur in the presence of heat ${ }^{30}$. These non-enzymatic browning reactions gave black $D$. longan a darker color and resulted in the formation of some antioxidant compounds ${ }^{28}$.

On the other hand, black $D$. longan pericarp and seed extracts possessed the same radical scavenging activity as those from dried $D$. longan. A likely explanation might be the degradation of some oxidative compounds during the heating process, although some free polyphenolic compounds and flavonoids were liberated from the bound forms ${ }^{23}$. Interestingly, the TEAC values of pericarp and seed extracts from both dried and black $D$. longan were comparable to ascorbic acid, gallic acid, and corilagin $(\mathrm{p}>0.05)$. Ellagic acid was remarked as the most potent radical scavenger (TEAC $=23.4 \pm 0.3 \mu \mathrm{g}$ Trolox $/ \mathrm{mg}$ ), followed by ascorbic acid (TEAC $=12.3 \pm 0.0 \mu \mathrm{g}$ Trolox $/ \mathrm{mg}$ ), gallic acid (TEAC $=12.8 \pm 0.2 \mu \mathrm{g}$ Trolox $/ \mathrm{mg}$ ), and corilagin (TEAC $=12.7 \pm 0.1 \mu \mathrm{g}$ Trolox $/ \mathrm{mg}$ ) . Thereby, ellagic acid was found to be the main compound responsible for the free radical scavenging activity of D. longan extracts together with gallic acid and corilagin ${ }^{31}$. Although the previous study reported that among various polyphenolic compounds, tannins demonstrated the strongest ABTS + radical scavenging activity ${ }^{32}$, in the present study it was observed that ellagic acid, which belongs to a flavonoid group, was more potent than gallic acid and corilagin, which belongs to hydrolysable tannin ${ }^{1}$. Furthermore, D. longan extracts from both pericarp and seed could therefore be considered as natural extracts with potent radical scavenging activity.

Aside from radical scavenging activity, D. longan extracts also possessed a reduction ability as shown in Fig. 6 . The reduction ability of $D$. longan extracts was in accordance with their phenolic and flavonoid contents. Gallic acid possessed the significantly highest $\mathrm{EC}_{1}$ value of $237.0 \pm 1.6 \mathrm{mM} \mathrm{FeSO}_{4} / \mathrm{mg}$, which was comparable to that of ascorbic acid $\left(238.3 \pm 0.2 \mathrm{mM} \mathrm{FeSO}_{4} / \mathrm{mg}\right)$, followed by corilagin $\left(226.2 \pm 2.9 \mathrm{mM} \mathrm{FeSO}_{4} / \mathrm{mg}\right)$ and ellagic acid $\left(192.3 \pm 0.7 \mathrm{mM} \mathrm{FeSO}_{4} / \mathrm{mg}\right)$. However, both phenolic compounds and flavonoids were responsible for their reduction capacity ${ }^{33}$. The black $D$. longan seed extract, which contained the highest total phenolic, total flavonoid, gallic acid, corilagin, and ellagic acid contents, thus possessed the significantly highest reduction ability with an $\mathrm{EC}_{1}$ value of $150.0 \pm 1.0 \mathrm{mM} \mathrm{FeSO}_{4} / \mathrm{mg}$ extract $(\mathrm{p}<0.05)$. Consequently, the black $D$. longan seed extract was suggested as the most potent antioxidant extract with the strongest free radical scavenging and reduction ability. Because of its potent antioxidant effect, black D. longan seed has been proposed as a natural antioxidant source for use in food and cosmetic products. Since the portions of pericarp and seed account for $30 \%$ of the whole fruit dry weight ${ }^{34}$, the utilization of these by-products would not only reduce the agricultural waste product but also increase its value. 

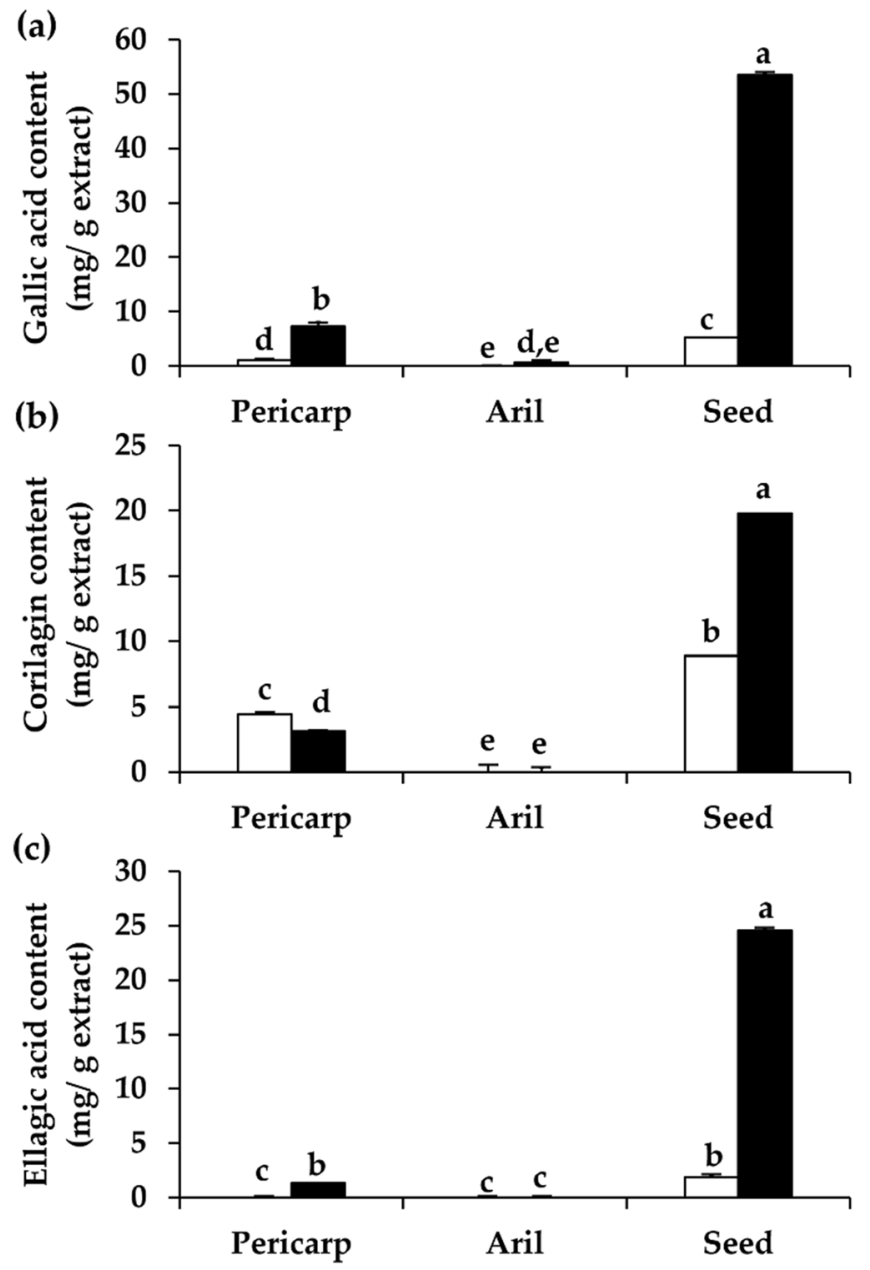

Figure 5. Gallic acid content (a), corilagin content (b), and ellagic acid content (c) of the ethanolic extracts from pericarp, aril, and seed of dried (unfilled squares) and black (filled squares) D. longan. The letters (a, b, c, $\mathrm{d}$, and e) denote significant differences in the contents of gallic acid, corilagin, or ellagic acid among various $D$. longan extracts $(\mathrm{p}<0.05)$ when analyzed using one-way analysis of variance (ANOVA) followed by Tukey's posthoc tests $(\mathrm{n}=3)$.

Anti-inflammatory activities of dried $\boldsymbol{D}$. longan and black $D$. longan extracts. The inhibitory activities against the secretion of IL- 6 and TNF- $\alpha$, which are key players involved in the age-related inflammatory process ${ }^{35}$, of dried and black D. longan extracts were investigated. RAW 264.7 macrophage cells were used in the present study since they can secret these cytokines after the stimulation of LPS. The RAW 264.7 macrophage cell viability after treatment with dried and black $D$. longan extracts is shown in Table 1 . No cytotoxicity was detected in any of the $D$. longan extracts since the cell viability was more than $100 \%$. Dexamethasone, corilagin, gallic acid, and ellagic acid were also found to be safe for RAW 264.7 macrophage cells.

The IL-6 and TNF- $\alpha$ inhibitory activities of dried and black D. longan extracts are shown in Fig. 7. TNF- $\alpha$ is known as an indicator of chronic inflammatory processes related to ageing, whereas IL-6 has been associated with poor physical performance and muscle weakness by geriatricians and could predict the onset of disability ${ }^{36,37}$. Among various parts of $D$. longan fruit, aril of both dried and black $D$. longan was predominant in IL-6 and TNF- $\alpha$ inhibition. Gallic acid was suggested to be the main compound responsible for both IL- 6 and TNF- $\alpha$ inhibitory activities. In contrast, corilagin was responsible only for TNF- $\alpha$ inhibition. Although $D$. longan extracts and their major chemical components exhibited only low to moderate anti-inflammatory activities compared to dexamethasone, a corticosteroid used in the treatment of inflammation, they could be consumed as natural anti-inflammatory supplements with no steroidal side effects.

Anti-hyaluronidase activities of dried $D$. longan and black $D$. longan extracts. Hyaluronidase, a homologous enzyme that hydrolyzes or depolymerizes hyaluronan, plays an important role in the modulating activity of many pathological processes ${ }^{38}$. Hyaluronan plays a pivotal role in the maintenance of the elastoviscosity of liquid connective tissues and controls the water transportation related to the tissue hydration ${ }^{39}$. The degradation of hyaluronan resulting in the production of breakdown products, including lower molecular mass polymers. These breakdown products of hyaluronan exhibited distinct biological properties from the larger 

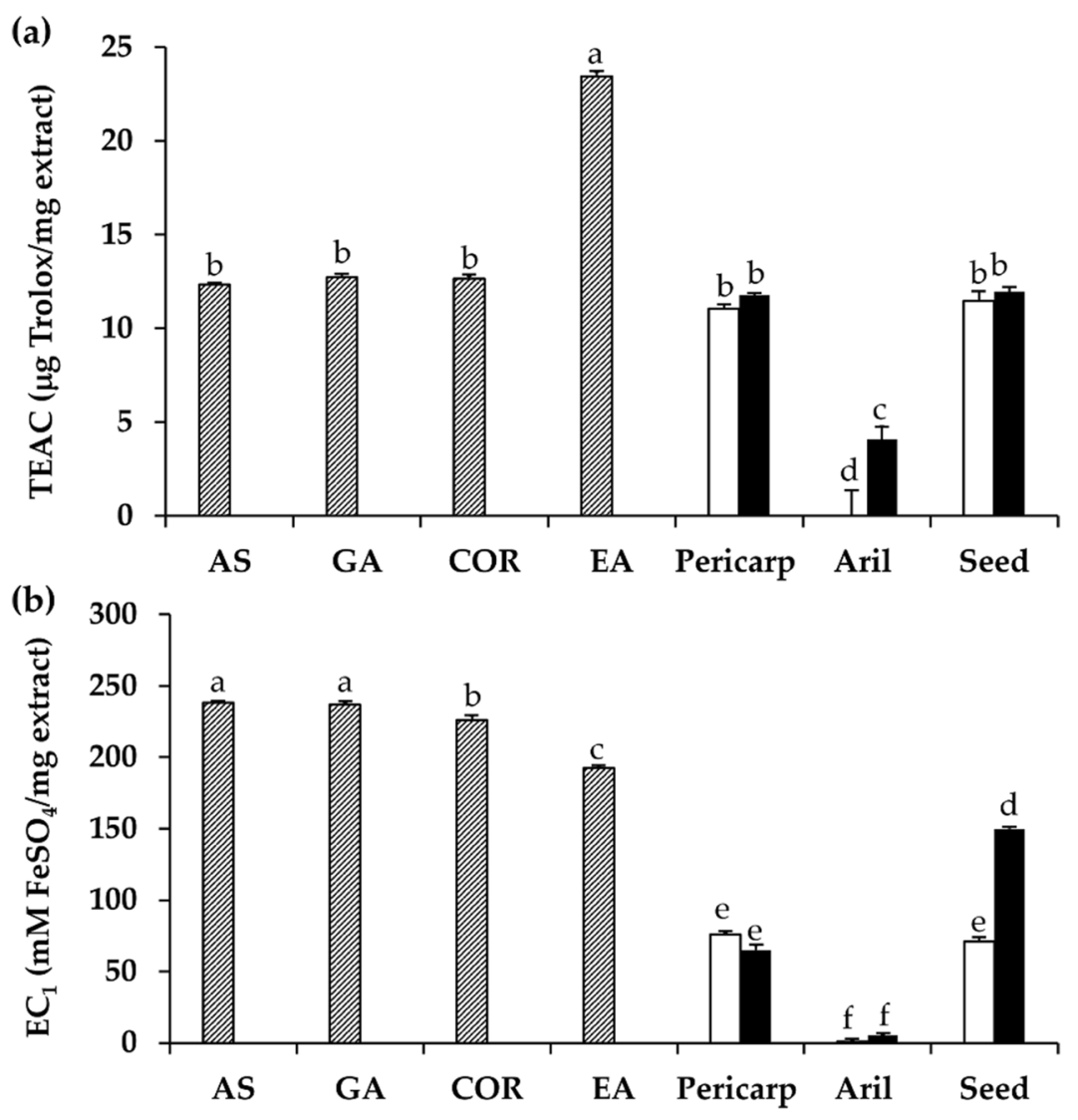

Figure 6. Trolox equivalent antioxidant capacity (TEAC) (a) and equivalent concentration $\left(\mathrm{EC}_{1}\right)(\mathbf{b})$ of ascorbic acid (AS), gallic acid (GA), corilagin (CO), ellagic acid (EA), and the ethanolic extracts from pericarp, aril, and seed of dried (unfilled squares) and black (filled squares) D. longan. The letters (a, b, c, d, e, and f) denote significant differences in TEAC or $\mathrm{EC}_{1}$ values among various tested samples $(\mathrm{p}<0.05)$ when analyzed using oneway analysis of variance (ANOVA) followed by Tukey's post-hoc tests $(n=3)$.

\begin{tabular}{|l|l|}
\hline Samples & Cell viability (\%) \\
\hline Dexamethasone & $98.9 \pm 3.8$ \\
\hline Corilagin & $102.0 \pm 0.2$ \\
\hline Gallic acid & $102.0 \pm 0.2$ \\
\hline Ellagic acid & $105.4 \pm 1.8$ \\
\hline Dried D. longan \\
\hline Aril & $102.8 \pm 0.1$ \\
\hline Pericarp & $101.3 \pm 0.2$ \\
\hline Seed & $102.6 \pm 1.3$ \\
\hline Black D. longan & \multicolumn{2}{|l}{} \\
\hline Aril & $103.0 \pm 0.3$ \\
\hline Pericarp & $103.1 \pm 0.9$ \\
\hline Seed & $103.0 \pm 0.3$ \\
\hline
\end{tabular}

Table 1. RAW 264.7 macrophage cell viability. The final concentration of each sample was $1 \mu \mathrm{g} / \mathrm{mL}$.

precursor molecules ${ }^{40}$. The hyaluronan depolymerization occurs in tissue injury and initiates the inflammatory response ${ }^{38}$. Additionally, hyaluronan is known as a lubricant and shock-absorber in joints and connective tissues $^{41}$. Its degradation hence leads to the deterioration of the viscoelastic properties of the synovial fluid ${ }^{42}$.

The inhibitory activities against hyaluronidase of dried and black D. longan extracts are shown in Fig. 8. Although D. longan extracts exhibited low anti-hyaluronidase activity, the inhibitory effect of black D. longan seed was significantly enhanced compared to the dried D. longan seed extract. Since the anti-hyaluronidase activity 

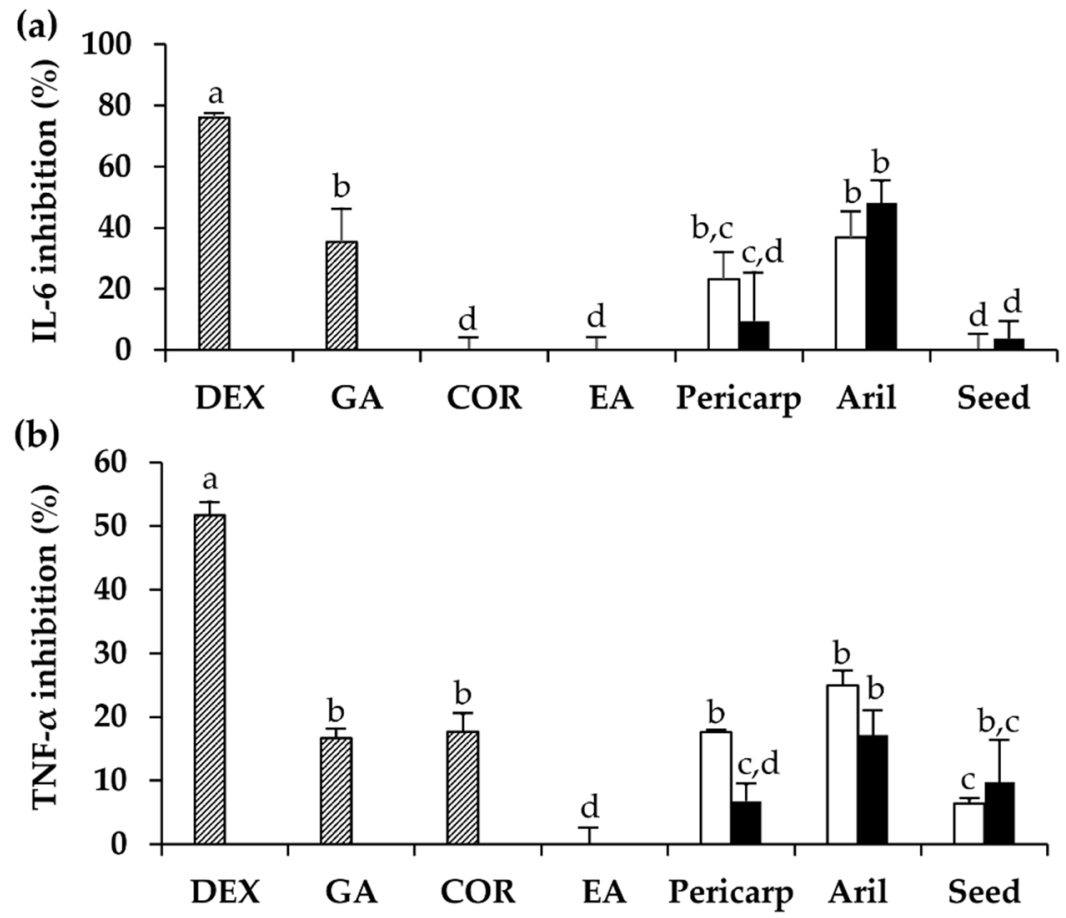

Figure 7. Inhibitory activities against the secretion of interleukin-6 (IL-6) (a) and tumor necrosis factor- $\alpha$ (TNF- $\alpha$ ) (b) of dexamethasone (DEX), gallic acid (GA), corilagin (CO), ellagic acid (EA), and the ethanolic extracts from pericarp, aril, and seed of dried (unfilled squares) and black (filled squares) D. longan. The final concentration of each sample was $1 \mu \mathrm{g} / \mathrm{mL}$. The letters ( $\mathrm{a}, \mathrm{b}, \mathrm{c}$, and d) denote significant differences in IL-6 or TNF- $\alpha$ inhibition among various tested samples $(\mathrm{p}<0.05)$ when analyzed using one-way analysis of variance (ANOVA) followed by Tukey's post-hoc tests $(n=3)$.

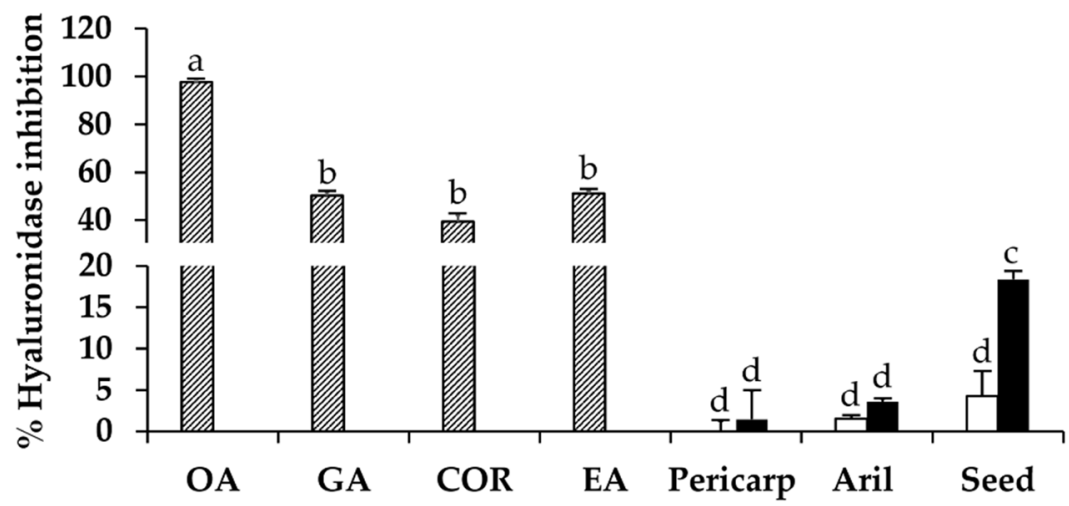

Figure 8. Inhibition against hyaluronidase activity of oleanolic acid (OA), gallic acid (GA), corilagin (CO), ellagic acid (EA), and the ethanolic extracts from pericarp, aril, and seed of dried (unfilled squares) and black (filled squares) D. longan. The letters (a, b, c, and d) denote significant differences in hyaluronidase inhibition among various tested samples $(\mathrm{p}<0.05)$ when analyzed using one-way analysis of variance (ANOVA) followed by Tukey's post-hoc tests $(\mathrm{n}=3)$.

of black D. longan seed extract $(18.4 \pm 2.0 \%)$ was the most significantly potent $(\mathrm{p}<0.05)$, black $D$. longan seed extract could be suggested to have anti-hyaluronidase activity in addition to its antioxidant activities.

In conclusion, black $D$. longan was successfully developed after undergoing a heating and ageing procedure at a controlled temperature of $70{ }^{\circ} \mathrm{C}$ and a relative humidity of $75 \%$. A novel black D. longan contained a larger quantity of biologically active compounds and possessed more potent biological activities than a conventional dried $D$. longan. The ethanolic extract from the seed of black $D$. longan contained the most significantly abundant of biologically active compounds, including total phenolic, total flavonoid, gallic acid, corilagin, and ellagic acid content $(\mathrm{p}<0.05)$. Furthermore, it possessed the most significantly potent antioxidant and anti-hyaluronidase activities $(\mathrm{p}<0.05)$. Since oxidative stress is known to be related to ageing and skin wrinkles, black $D$. longan 
seed extract with a potent antioxidant activity $(\mathrm{p}<0.05)$ was suggested for further topical use as a cosmeceutical ingredient for anti-skin ageing. On the other hand, degradation of hyaluronan in the skin resulted in the loss of the skin's natural moisturizing factor, while the loss of hyaluronan from the synovial fluid in joint resulted in joint pain and several conditions. Therefore, black $D$. longan seed extract, which significantly inhibited hyaluronidase activity $(\mathrm{p}<0.05)$, is suggested for both topical use for anti-skin ageing and joint pain relief. On the other hand, the aril of $D$. longan, which possessed the significantly highest anti-inflammatory activities, is suggested as a natural edible anti-inflammatory agent.

\section{Material and methods}

Chemical material. L-Ascorbic acid, aluminum chloride $\left(\mathrm{AlCl}_{3}\right), 2,2$ '-azino-bis3-ethylbenzothiazoline6-sulfonic acid (ABTS), calcium chloride $\left(\mathrm{CaCl}_{2}\right)$, corilagin, dexamethasone, disodium phosphate $\left(\mathrm{Na}_{2} \mathrm{HPO}_{4}\right)$, ferric chloride $\left(\mathrm{FeCl}_{3}\right)$, ferrous chloride $\left(\mathrm{FeCl}_{2}\right)$, ferrous sulfate $\left(\mathrm{FeSO}_{4}\right)$, formic acid, Folin-Ciocalteu reagent, 4,4',5,5',6,6'-hexahydroxy-diphenic acid 2,6,2',6'-dilactone (ellagic acid), hyaluronic acid, hydrochloric acid (HCl), 6-hydroxy-2,5,7,8-tetramethylchroman-2-carboxylic acid (Trolox), bovine testicular hyaluronidase (E.C.3.2.1.3.5), potassium acetate $\left(\mathrm{CH}_{3} \mathrm{COOK}\right)$, potassium persulphate $\left(\mathrm{K}_{2} \mathrm{~S}_{2} \mathrm{O}_{8}\right)$, sodium acetate $\left(\mathrm{C}_{2} \mathrm{H}_{3} \mathrm{NaO}_{2}\right)$, sodium carbonate $\left(\mathrm{Na}_{2} \mathrm{CO}_{3}\right)$, sodium chloride $(\mathrm{NaCl})$, sodium dihydrogen phosphate $\left(\mathrm{NaH}_{2} \mathrm{PO}_{4}\right)$, sodium phosphate $\left(\mathrm{Na}_{3} \mathrm{PO}_{4}\right)$, 2,4,6-tripyridyl-striazine (TPTZ), and 3,4,5-trihydroxybenzoic acid (gallic acid) were analytical grade and purchased from Sigma-Aldrich (St. Louis, MO, USA). Amphotericin B, Dulbecco's modified Eagle's medium, high glucose (DME/HIGH), L-glutamine, penicillin/streptomycin, trypan blue, and secondary antibody conjugated with HRP were bought from Invitrogen (Carlsbad, CA, USA). Lipopolysaccharides (LPS) were bought from Cell Signaling Technology (Danvers, MA, USA). GlutaMAX-I supplement was bought from Thermo Fisher Scientific, Inc. (Thermo Fisher Scientific, Waltham, MA, USA). Newborn bovine calf serum (catalog number: 16010159), fetal bovine serum (FBS) (catalog number: 26140079), and bovine serum albumin (BSA) (catalog number: B14) were bought from Gibco (Thermo Fisher Scientific, Waltham, MA, USA). Analytical grade acetic acid, ethanol, and dimethyl sulfoxide (DMSO) were purchased from Labscan, Ltd. (Dublin, Ireland). HPLC-grade acetonitrile was purchased from Labscan, Ltd. (Dublin, Ireland).

Plant material. The D. longan fruits were collected from Chiang Mai Province in Northern Thailand in January 2020 by the gardeners according to WHO Guidelines on Good Agricultural and Collection Practices (GACP) for Medicinal Plants ${ }^{43}$. The permission to collect $D$. longan fruits were obtained from the farm owner. The plant materials were identified and authenticated by Ms. Wannaree Charoensup, a botanist at the Herbarium of Faculty of Pharmacy, Chiang Mai University. A voucher specimen number 0023268 of D. longan has been deposited in an Herbarium, Department of Pharmaceutical Science, Faculty of Pharmacy, Chiang Mai University. The preparation of conventional dried and black D. longan was performed by the Faculty of Agro-Industry, Chiang Mai University, Chiang Mai, Thailand.

Conventional dried $D$. longan preparation. Conventional dried $D$. longan was obtained after the whole fruit of fresh $D$. longan was incubated in an oven set at the temperature of $50{ }^{\circ} \mathrm{C}$ until dryness (moisture content below 16-18\%). The sample of dried D. longan was kept in a sealed plastic bag to prevent contact with air and humidity in the room temperature until further experiments.

Black D. longan preparation by thermal and ageing process. Black D. longan was obtained after the whole fruit of dried D. longan was incubated for 20 days at a controlled temperature of $70{ }^{\circ} \mathrm{C}$ and $75 \%$ relative humidity. The sample of black $D$. longan was kept in a sealed plastic bag and placed in a desiccator chamber cabinet to prevent contact with air and humidity at room temperature until further experiments.

Preparation of dried $D$. longan and black $D$. longan extracts. The seed, aril, and pericarp were separated from each other. Each part of the D. longan fruit was ground into fine powder using a 20-in. herbal medicine grinder tub with a powerful motor (Thai Pradith Industry Co., Ltd., Bangkok, Thailand). Dried $D$. longan powder was subsequently macerated in $95 \% \mathrm{v} / \mathrm{v}$ ethanol for three cycles of $24 \mathrm{~h}$. The proportion of plant material to solvent was 1:5 by weight. The same protocol of maceration was used for each part of dried and black $D$. longan. The extracting solvent from three cycles was combined and removed using a rotary evaporator (Buchi Labortechnik GmbH, Essen, Germany). All extracts were stored in the refrigerator $\left(\sim 4{ }^{\circ} \mathrm{C}\right)$ until further experiments.

Determination of phytochemical compositions of dried $D$. longan and black $D$. longan extracts. Total phenolic content determination. Each D. longan extract was analyzed for total phenolic content using the Folin-Ciocalteu method according to the previously described method ${ }^{44}$. Firstly, $20 \mu \mathrm{L}$ of the ethanolic solution of $D$. longan extracts $(1 \mathrm{mg} / \mathrm{mL})$ was mixed with $180 \mu \mathrm{L}$ of Folin-Ciocalteu reagent $(10 \% \mathrm{w} / \mathrm{v})$. After incubation at ambient temperature for $4 \mathrm{~min}, 80 \mu \mathrm{L}$ of sodium carbonate solution $(74.2 \mathrm{~g} / \mathrm{L}, 0.7 \mathrm{M})$ was added. After the resulting mixtures were incubated for $2 \mathrm{~h}$. they were measured for an absorbance at $750 \mathrm{~nm}$ using multimode detector (SPECTROstar Nano, BMG Labtech, Offenburg, Germany). The results were presented in the form of gallic acid equivalent values (GAE) representing an amount of gallic acid ( $\mu \mathrm{g})$ per $\mathrm{g}$ of the D. longan extracts. GAE was calculated following Eq. (1);

$$
\mathrm{X}=(\mathrm{Y}-0.0075) / 0.3812\left(\mathrm{R}^{2}=0.9985\right)
$$


where $\mathrm{X}$ is GAE or $\mu \mathrm{g}$ of gallic acid per $\mathrm{g}$ of the D. longan extracts and $\mathrm{Y}$ is an absorbance of each sample tested with the Folin-Ciocalteu assay. The experiments were performed in triplicate.

Total flavonoid content determination. Total flavonoid content of each $D$. longan extract was investigated using the aluminum chloride method, which has been previously described, with some modifications ${ }^{45}$. Firstly, $20 \mu \mathrm{L}$ of the ethanolic solution of $D$. longan extracts $(1 \mathrm{mg} / \mathrm{mL})$ was mixed with $80 \mu \mathrm{L}$ of $\mathrm{AlCl}_{3}$ aqueous solution $(0.1 \mathrm{~g} /$ $\mathrm{mL}, 10 \% \mathrm{w} / \mathrm{v})$ and $100 \mu \mathrm{L}$ of $\mathrm{CH}_{3} \mathrm{COOK}$ aqueous solution $(98.15 \mathrm{~g} / \mathrm{l}, 1 \mathrm{M})$. After the resulting mixtures were incubated for $30 \mathrm{~min}$ in the dark, they were measured for an absorbance at $415 \mathrm{~nm}$ using a multimode detector (SPECTROstar Nano, BMG Labtech, Offenburg, Germany). Quercetin was applied as a standard compound to construct a calibration curve. Finally, the results were presented as quercetin equivalent (QE) values, which represented a $\mu \mathrm{g}$ of quercetin per $\mathrm{g}$ of the D. longan extracts. QE was calculated following Eq. (2);

$$
\mathrm{X}=(\mathrm{Y}+0.033) / 0.107\left(\mathrm{R}^{2}=0.9933\right)
$$

where $\mathrm{X}$ is $\mathrm{QE}$ or $\mu \mathrm{g}$ of quercetin per $\mathrm{g}$ of the $\mathrm{D}$. longan extracts and $\mathrm{Y}$ is an absorbance of each sample tested in the aluminum chloride assay. The experiments were performed in triplicate.

Determination of gallic acid, corilagin, and ellagic acid content by high performance liquid chromatography (HPLC). The quantitative analysis of gallic acid, corilagin, and ellagic acid was performed using an HP 1100 chromatographic system (Hewlett-Packard, Waldbronn, Germany). A gradient mobile phase system composed of two phases was used, including phase $\mathrm{A}(0.05 \%$ formic acid in acetonitrile) and phase $\mathrm{B}(0.05 \%$ formic acid aqueous solution). The program was set for gradient elution of $10 \% \mathrm{~A}(0-8 \mathrm{~min}), 20 \% \mathrm{~A}(8-28 \mathrm{~min}), 30 \% \mathrm{~A}$ (28-30 $\mathrm{min})$, and $10 \% \mathrm{~A}(30-35 \mathrm{~min})$, eluting the sample at a flow rate of $1.0 \mathrm{~mL} / \mathrm{min}$. The UV detector was set at $280 \mathrm{~nm}$ with a Eurospher II 100-5 C18 (250×4.6 mm, i.d. $5 \mu \mathrm{m}$, Knauer, Berlin, Germany). All samples, standard solution, and mobile phase were filtrated through a $0.45 \mathrm{~mm}$ Millipore filter, type GV (Millipore, Bedford, MA) before injection into the HPLC system. The injected volume was set at $20 \mu \mathrm{L}$. The sample of $D$. longan extracts was prepared at a concentration of $1 \mathrm{mg} / \mathrm{mL}$. Various concentrations of standard gallic acid $(10-150 \mu \mathrm{g} / \mathrm{mL})$, ellagic acid $(5-100 \mu \mathrm{g} / \mathrm{mL})$, and corilagin $(2-80 \mu \mathrm{g} / \mathrm{mL})$ solution were used for the construction of standard curves for quantitative determination. Subsequently, the content of gallic acid, corilagin, and ellagic acid was then calculated using the following Eqs. (3)-(5), respectively

$$
\mathrm{X} 1=(100 \mathrm{~A}+1296) / 26.8 \mathrm{C}\left(\mathrm{R}^{2}=0.9964\right),
$$

where $\mathrm{X} 1$ is the gallic acid concentration, $\mathrm{A}$ is the area under the curve (AUC) of the gallic acid peak detected around $4 \mathrm{~min}$, and $\mathrm{C}$ is the concentration of the respective sample solution.

$$
\mathrm{X} 2=(100 \mathrm{~A}+2325) / 17.8 \mathrm{C}\left(\mathrm{R}^{2}=0.9996\right),
$$

where $\mathrm{X} 2$ is the concentration of corilagin, $\mathrm{A}$ is the $\mathrm{AUC}$ of the corilagin peak detected around $10 \mathrm{~min}$, and $\mathrm{C}$ is the concentration of the respective sample solution.

$$
\mathrm{X} 3=(100 \mathrm{~A}+13,372) / 33.7 \mathrm{C}\left(\mathrm{R}^{2}=0.9957\right),
$$

where $\mathrm{X} 3$ is the concentration of ellagic acid, A is the AUC of the ellagic acid peak detected around $20 \mathrm{~min}$, and $\mathrm{C}$ is the concentration of the respective sample solution.

Antioxidant activity determination of dried $D$. longan and black $D$. longan extracts with 2,2'-azinobis (3-ethylbenzothiazoline-6-sulfonic acid) (ABTS) assay. The radical scavenging effects against $\mathrm{ABTS}^{+}$of $D$. longan extracts, gallic acid, corilagin, and ellagic acid were evaluated using the ABTS assay and reported in terms of Trolox equivalent antioxidant capacity (TEAC), which represents the quantity of Trolox that equivalent to $1 \mathrm{mg}$ of the $D$. longan extracts ${ }^{46}$. Firstly, $20 \mu \mathrm{L}$ of the ethanolic solution of $D$. longan extracts $(1 \mathrm{mg} / \mathrm{mL})$ was mixed with the mixture of $72 \mu \mathrm{L}$ ABTS solution $(3.60 \mathrm{~g} / \mathrm{L}, 7.0 \mathrm{mM})$ and $108 \mu \mathrm{L}$ potassium persulfate solution $(0.66 \mathrm{~g} / \mathrm{L}, 2.45 \mathrm{mM})$, which had been previously mixed and incubated in the dark for $16 \mathrm{~h}$ at ambient temperature. After the resulting mixtures were incubated for $5 \mathrm{~min}$, they were measured for an absorbance at $750 \mathrm{~nm}$ using multimode detector (SPECTROstar Nano, BMG Labtech, Offenburg, Germany). TEAC values were calculated following Eq. (6);

$$
\mathrm{X}=(\mathrm{Y}-1.2028) / 7.9964\left(\mathrm{R}^{2}=0.9977\right),
$$

where $\mathrm{X}$ is TEAC value and $\mathrm{Y}$ is an absorbance of each sample tested in ABTS assay. 1-Ascorbic acid was used as a positive control. The experiments were performed in triplicate.

Ferric reduction/antioxidant power (FRAP) assay. The reduction capacity of D. longan extracts, gallic acid, corilagin, and ellagic acid were investigated by means of a ferric ion reduction assay ${ }^{44}$. Firstly, $20 \mu \mathrm{L}$ of the ethanolic solution of $D$. longan extracts $(1 \mathrm{mg} / \mathrm{mL})$ was mixed with $150 \mu \mathrm{L}$ acetate buffer $\mathrm{pH} 3.6(0.3 \mathrm{M}), 15 \mu \mathrm{L}$ TPTZ solution $(3.123 \mathrm{~g} / \mathrm{L}, 10 \mathrm{mM})$ in $\mathrm{HCl}(14.58 \mathrm{~g} / \mathrm{L}, 40 \mathrm{mM})$, and freshly prepared $15 \mu \mathrm{L} \mathrm{FeCl}(3.24 \mathrm{~g} / \mathrm{L}, 20 \mathrm{mM})$. After incubation at ambient temperature for $4 \mathrm{~min}, 80 \mu \mathrm{L}$ of sodium carbonate solution $(74.2 \mathrm{~g} / \mathrm{L}, 0.7 \mathrm{M})$ was added. After the resulting mixtures were incubated for $5 \mathrm{~min}$, they were measured for an absorbance at $595 \mathrm{~nm}$ using multimode detector (SPECTROstar Nano, BMG Labtech, Offenburg, Germany). The ferric reducing/antioxidant power of each $D$. longan extract was expressed in the form of equivalent concentration $\left(\mathrm{EC}_{1}\right)$, represent- 
ing the ferric-TPTZ reduction capacity, which is equivalent to $1 \mathrm{mg}$ of the $D$. longan extract. The $\mathrm{EC}_{1}$ values were calculated following Eq. (7);

$$
\mathrm{X}=(\mathrm{Y}-0.0287) / 0.01405\left(\mathrm{R}^{2}=0.9926\right),
$$

where $\mathrm{X}$ is $\mathrm{EC}_{1}$ value and $\mathrm{Y}$ is an absorbance of each sample tested in the FRAP assay. L-Ascorbic acid was used as a positive control. The experiments were performed in triplicate.

Anti-inflammatory activity determination of dried D. longan and black D. longan extracts. Murine monocytemacrophage (RAW 264.7) cells (American Type Culture Collection, ATCCTIB-71) treated with LPS were used to investigate the effect of $D$. longan extracts and their chemical compositions on the pro-inflammatory cytokine secretion (IL-6 and TNF- $\alpha$ ). Cells were cultured according to a method previously described with some modifications ${ }^{47,48}$. Briefly, RAW 264.7 cells with a density of $2 \times 10^{6}$ cells per well in $750 \mu \mathrm{L}$ of DMEM supplemented with GlutaMAX ${ }^{m}-\mathrm{I}$, inactivated FBS $(10 \%)$, penicillin $(100 \mathrm{U} / \mathrm{mL})$, streptomycin $(100 \mu \mathrm{g} / \mathrm{mL})$, and amphotericin $\mathrm{B}(0.25 \mu \mathrm{g} / \mathrm{mL})$ were seeded in wells of 24 well-plates and incubated in a $\mathrm{CO}_{2}$ incubator $\left(37^{\circ} \mathrm{C}, 5 \% \mathrm{CO}_{2}\right.$ in air, $90 \%$ humidity) for $24 \mathrm{~h}$. Thereafter, $1 \mu \mathrm{L}$ of the $D$. longan extracts or dexamethasone $(100 \mu \mathrm{g} / \mathrm{mL})$ was added and further incubated in a $\mathrm{CO}_{2}$ incubator $\left(37^{\circ} \mathrm{C}, 5 \% \mathrm{CO}_{2}\right.$ in air, $90 \%$ humidity). Three replicates per sample were performed. After $24 \mathrm{~h}$ of the extract treatment, $250 \mu \mathrm{L}$ of LPS in DMEM $(4 \mu \mathrm{g} / \mathrm{mL})$ was treated in each well and incubated in a $\mathrm{CO}_{2}$ incubator $\left(37{ }^{\circ} \mathrm{C}, 5 \% \mathrm{CO}_{2}\right.$ in air, $90 \%$ humidity) for another 24. After that, the treated cells along with the supernatant were divided into two parts. The medium $(500 \mu \mathrm{L})$ was collected for cytokine dosages, while the attached cells were subjected to the viability assay using MTT dye. The collected medium was then centrifuged for $10 \mathrm{~min}$ at $13,500 \times \mathrm{g}$, and the supernatant was investigated for cytokine secretion using an enzyme-linked immunosorbent assay (ELISA) following the manufacturer's protocol (R\&D Systems). The remain medium, which was left over in the wells, was investigated for cell viability using a 3-(4,5-dimethylthiazol-2-yl)-2,5-diphenyltetrazolium bromide (MTT) assay. To reduce variation due to cell density differences, secretion of IL-6 and TNF- $\alpha$ from RAW 264.7 cells was normalized to MTT levels ${ }^{48}$. RAW 264.7 cells without lipopolysaccharide treatment served as a negative control, while $100 \%$ of cytokine secretion was from the positive control of RAW 264.7 cells treated with LPS. The inhibitory activities of each sample were calculated following Eq. (8);

$$
\% \text { Cytokine inhibition }=100-\mathrm{A}
$$

where A is the cytokine secretion. Dexamethasone served as a positive control for both IL- 6 and TNF- $\alpha$ secretory inhibition. The experiments were performed in triplicate.

Anti-hyaluronidase activity determination of dried D. longan and black D. longan extracts. The hyaluronidase inhibitory activity of $D$. longan extracts, gallic acid, corilagin, and ellagic acid was evaluated by measuring a product from the cleavage of sodium hyaluronate by hyaluronidase ${ }^{49}$. Prior to the experiment, the enzyme activity of hyaluronidase was determined. More than $90 \%$ enzyme activity was used in the anti-hyaluronidase activity determination. Firstly, $20 \mu \mathrm{L}$ of the ethanolic solution of $D$. longan extracts $(1 \mathrm{mg} / \mathrm{mL})$ was mixed with hyaluronidase ( $15 \mathrm{unit} / \mathrm{mL})$. After incubation at $37^{\circ} \mathrm{C}$ for $10 \mathrm{~min}$, hyaluronic acid solution $(0.03 \% \mathrm{w} / \mathrm{v})$ in phosphate buffer $\mathrm{pH} 5.35$ was added and further incubated for $45 \mathrm{~min}$. Immediately after the addition of acid bovine serum albumin, the extracts were measured for an absorbance at $600 \mathrm{~nm}$ using a multimode detector (SPECTROstar Nano, BMG Labtech, Offenburg, Germany). The hyaluronidase inhibitory activity was calculated according to Eq. (9);

$$
\% \text { Inhibition }=[1-\mathrm{X} / \mathrm{Y})] \times 100,
$$

where $\mathrm{X}$ is the absorbance of the mixtures with sample; $\mathrm{Y}$ is the absorbance of the mixtures without sample. Oleanolic acid was used as a positive control. The experiments were performed in triplicate.

Statistical analysis. All the values are given as means \pm standard deviations and were analyzed. The statistical analysis used was one-way analysis of variance (ANOVA) followed by Tukey's post-hoc tests using the SPSS software (SPSS Statistics 21.0, IBM Corporations, New York, NY, USA). A value of $\mathrm{p}<0.05$ was accepted as significant.

Received: 30 March 2021; Accepted: 28 July 2021

Published online: 05 August 2021

\section{References}

1. Zhang, X., Guo, S., Ho, C. T. \& Bai, N. Phytochemical constituents and biological zctivities of longan (Dimocarpus longan Lour.) fruit: A review. Food Sci. Hum. Well. 9(2), 95-102 (2020).

2. Yang, B., Jiang, Y., Shi, J., Chen, F. \& Ashraf, M. Extraction and pharmacological properties of bioactive compounds from longan (Dimocarpus longan Lour.) fruit-A review. Food Res. Inter. 44(7), 1837-1842 (2011).

3. Tang, Y. Y. et al. Polyphenols and alkaloids in byproducts of Longan fruits (Dimocarpus Longan Lour.) and their bioactivities. Molecules 24(6), 1186 (2019).

4. Prasad, K., Neha, P., Lal, M. K. \& Gaurav, A. K. Longan (Dimocarpus longan Lour) processing: A review. Int. J. Curr. Microbiol. Appl. Sci. 6(8), 1-7 (2017).

5. Soong, Y. Y. \& Barlow, P. J. Quantification of gallic acid and ellagic acid from longan (Dimocarpus longan Lour.) seed and mango (Mangifera indica L.) kernel and their effects on antioxidant activity. Food Chem. 97(3), 524-530 (2006). 
6. Rangkadilok, N. et al. In vitro antifungal activities of longan (Dimocarpus longan Lour.) seed extract. Fitoterapia 83(3), 545-553 (2012).

7. Tseng, H. C., Wu, W. T., Huang, H. S. \& Wu, M. C. Antimicrobial activities of various fractions of longan (Dimocarpus longan Lour. Fen Ke) seed extract. Int. J. Food Sci. Nutr. 65(5), 589-593 (2014).

8. Ashok, A. D., Ravivarman, J. \& Kayalvizhi, K. Nutraceutical values of minor fruits on immunity development to combat diseases. Int. J. Curr. Microbiol. App. Sci. 9(6), 1303-1311 (2020).

9. Jiang, Y., Zhang, Z., Joyce, D. C. \& Ketsa, S. Postharvest biology and handling of longan fruit (Dimocarpus longan Lour.). Postharvest. Biol. Technol. 26(3), 241-252 (2002).

10. Sopadang, A., Tippayawong, K. Y. \& Chaowarut, W. Application of value chain management to longan industry. Am. J. Agric. Biol. Sci. 7(3), 301-311 (2012).

11. Qiu, L., Zhang, M., Tang, J., Adhikari, B. \& Cao, P. Innovative technologies for producing and preserving intermediate moisture foods: A review. Food Res. Int. 116, 90-102 (2019).

12. Taoukis, P. S. \& Richardson, M. Principles of intermediate-moisture foods and related technology. in Water Activity in Foods: Fundamentals and Applications (eds. Barbosa-Cánovas, G.V., Fontana, A.J., Schmidt, S.J. \& Labuza, T.P.) 385-424 (2020).

13. Saha, S. IMF: To enhance the shelf-Life of food. Technology 6(10), 103-108 (2020).

14. Rahim, M. A., Kabir, M. A., Hossain, M. A., Islam, F. \& Naher, N. Present status of quality management in postharvest system for fruit in Bangladesh. Europe-Asia Symp. Qual. Manag. Postharvest Syst. Eurasia 2007(804), 623-630 (2007).

15. Wu, J., Jin, Y. \& Zhang, M. Evaluation on the physicochemical and digestive properties of melanoidin from black garlic and their antioxidant activities in vitro. Food Chem. 340, 127934 (2021).

16. Jing, H. Black garlic: Processing, composition change, and bioactivity. eFood. 1(3), 242-246 (2020).

17. Yu, J., Shan, Y., Li, S. \& Zhang, L. Potential contribution of Amadori compounds to antioxidant and angiotensin I converting enzyme inhibitory activities of raw and black garlic. LWT. 129, 109553 (2020).

18. Wu, J. et al. Black garlic melanoidins prevent obesity, reduce serum LPS levels and modulate the gut microbiota composition in high-fat diet-induced obese C57BL/6J mice. Food Funct. 11(11), 9585-9598 (2020).

19. Ríos, J. L., Giner, R. M., Marín, M. \& Recio, M. C. A pharmacological update of ellagic acid. Planta Med. 84(15), 1068-1093 (2018).

20. Landete, J. M. Ellagitannins, ellagic acid and their derived metabolites: A review about source, metabolism, functions and health. Food Res. Int. 44(5), 1150-1160 (2011).

21. Bai, X., Pan, R., Li, M., Li, X. \& Zhang, H. HPLC profile of longan (cv. Shixia) pericarp-sourced phenolics and their antioxidant and cytotoxic effects. Molecules 24(3), 619 (2019).

22. Liu, C. et al. Antioxidant capacity and contents of polyphenols in pericarps and stones of Dimocarpus longan. Food Sci. Technol. 39, 203-211 (2014).

23. Kim, J. S., Kang, O. J. \& Gweon, O. C. Comparison of phenolic acids and flavonoids in black garlic at different thermal processing steps. J. Funct. Foods. 5(1), 80-86 (2013).

24. Kittipongpatana, N. et al. Resistant starch contents of starch isolated from black longan seeds. Molecules 26(11), 3405 (2021).

25. Zheng, G. et al. Polyphenols from longan seeds and their radical-scavenging activity. Food Chem. 116(2), 433-436 (2009).

26. Prasad, K. N. et al. Enhanced antioxidant and antityrosinase activities of longan fruit pericarp by ultra-high-pressure-assisted extraction. J. Pharm. Biomed. Anal. 51(2), 471-477 (2010).

27. Sudjaroen, Y. et al. Isolation and characterization of ellagitannins as the major polyphenolic components of longan (Dimocarpus longan Lour) seeds. Phytochem. 77, 226-237 (2012).

28. Zhang, X., Li, N., Lu, X., Liu, P. \& Qiao, X. Effects of temperature on the quality of black garlic. J. Sci. Food Agric. 96(7), 2366-2372 (2016).

29. Abramovič, H., Grobin, B., Poklar Ulrih, N. \& Cigić, B. Relevance and standardization of in vitro antioxidant assays: ABTS, DPPH, and Folin-Ciocalteu. J. Chem. 2018, 4608405 (2018).

30. Nie, S. et al. Effect of $\mathrm{pH}$, temperature and heating time on the formation of furan in sugar-glycine model systems. Food Sci. Hum. Well. 2(2), 87-92 (2013).

31. Priyadarsini, K. I., Khopde, S. M., Kumar, S. S. \& Mohan, H. Free radical studies of ellagic acid, a natural phenolic antioxidant. J. Agric. Food Chem. 50(7), 2200-2206 (2002).

32. Cai, Y. Z., Sun, M., Xing, J., Luo, Q. \& Corke, H. Structure-radical scavenging activity relationships of phenolic compounds from traditional Chinese medicinal plants. Life Sci. 78(25), 2872-2888 (2006).

33. Marsup, P. et al. Enhancement of chemical stability and dermal delivery of Cordyceps militaris extracts by nanoemulsion. Nanomaterials 10(8), $1565(2020)$.

34. Zhu, X. R. et al. Pericarp and seed of litchi and longan fruits: Constituent, extraction, bioactive activity, and potential utilization. J. Zhejiang Univ. Sci. B. 20(6), 503-512 (2019).

35. Chung, H. Y., Sung, B., Jung, K. J., Zou, Y. \& Yu, B. P. The molecular inflammatory process in aging. Antioxid. Redox. Signal. 8(3-4), $572-581$ (2006).

36. Hubbard, R. E., O’Mahony, M. S., Calver, B. L. \& Woodhouse, K. W. Plasma esterases and inflammation in ageing and frailty. Eur. J. Clin. Pharmacol. 64(9), 895 (2008).

37. de Gonzalo-Calvo, D. et al. Differential inflammatory responses in aging and disease: TNF- $\alpha$ and IL-6 as possible biomarkers. Free Radic. Biol. Med. 49(5), 733-737 (2010).

38. Piwowarski, J. P., Kiss, A. K. \& Kozłowska-Wojciechowska, M. Anti-hyaluronidase and anti-elastase activity screening of tanninrich plant materials used in traditional Polish medicine for external treatment of diseases with inflammatory background. $J$. Ethnopharmacol. 137(1), 937-941 (2011).

39. Necas, J., Bartosikova, L., Brauner, P. \& Kolar, J. Hyaluronic acid (hyaluronan): A review. Vet. Med. 53(8), 397-411 (2008).

40. Noble, P. W. Hyaluronan and its catabolic products in tissue injury and repair. Matrix Biol. 21(1), 25-29 (2002).

41. Meyer, K. The biological significance of hyaluronic acid and hyaluronidase. Physiol. Rev. 27(3), 335-359 (1947).

42. Fam, H., Bryant, J. T. \& Kontopoulou, M. Rheological properties of synovial fluids. Biorheology 44(2), 59-74 (2007).

43. World Health Organization. Good agricultural practices for medicinal plants. in WHO Guidelines on Good Agricultural and Collection Practices [GACP] for Medicinal Plants (ed. Zhang, X.) 7-16 (2003).

44. Chaiyana, W. et al. Ocimum sanctum Linn. as a natural source of skin anti-ageing compounds. Ind. Crops Prod. 127, 217-224 (2019).

45. Chaiyana, W. et al. Chemical constituents, antioxidant, anti-MMPs, and anti-hyaluronidase activities of Thunbergia laurifolia Lindl. leaf extracts for skin aging and skin damage prevention. Molecules 25(8), 1923 (2020).

46. Somwongin, S., Chantawannakul, P. \& Chaiyana, W. Antioxidant activity and irritation property of venoms from Apis species. Toxicon 145, 32-39 (2018).

47. Laothaweerungsawat, N., Neimkhum, W., Anuchapreeda, S., Sirithunyalug, J. \& Chaiyana, W. Transdermal delivery enhancement of carvacrol from Origanum vulgare L. essential oil by microemulsion. Int. J. Pharm. 579, 119052 (2020).

48. Mueller, M., Hobiger, S. \& Jungbauer, A. Anti-inflammatory activity of extracts from fruits, herbs and spices. Food Chem. 122(4), 987-996 (2010).

49. Chaiyana, W. et al. Enhancement of the antioxidant, anti-tyrosinase, and anti-hyaluronidase activity of Morus alba L. leaf extract by pulsed electric field extraction. Molecules 25(9), 2212 (2020). 


\section{Acknowledgements}

This research was funded by the Agricultural Research Development Agency (ARDA), Grant number PRP6305032210. The APC was funded by the Research Center of Pharmaceutical Nanotechnology, Faculty of Pharmacy, Chiang Mai University and Innovation Center for Holistic Health, Nutraceuticals, and Cosmeceuticals, Faculty of Pharmacy, Chiang Mai University. Sriyab is grateful for the CMU Presidential Scholarship 2020 for Post-Doctoral research.

\section{Author contributions}

W.C. conceived and designated the experiments. P.H. conducted the experiments. P.H., C.P., W.N., and S.S. collected and analyzed the data. P.H. and W.C. wrote the initial manuscript and revised the manuscript.

\section{Competing interests}

The authors declare no competing interests.

\section{Additional information}

Correspondence and requests for materials should be addressed to W.C.

Reprints and permissions information is available at www.nature.com/reprints.

Publisher's note Springer Nature remains neutral with regard to jurisdictional claims in published maps and institutional affiliations.

(c) (i) Open Access This article is licensed under a Creative Commons Attribution 4.0 International cc) License, which permits use, sharing, adaptation, distribution and reproduction in any medium or format, as long as you give appropriate credit to the original author(s) and the source, provide a link to the Creative Commons licence, and indicate if changes were made. The images or other third party material in this article are included in the article's Creative Commons licence, unless indicated otherwise in a credit line to the material. If material is not included in the article's Creative Commons licence and your intended use is not permitted by statutory regulation or exceeds the permitted use, you will need to obtain permission directly from the copyright holder. To view a copy of this licence, visit http://creativecommons.org/licenses/by/4.0/.

(C) The Author(s) 2021 